\title{
Psychological Problems Among Nursing Staff in a Hospital
}

\author{
Shakya DR,' Lama S, ${ }^{2}$ Shyangwa PM' \\ 'Department of Psychiatry, ${ }^{2}$ College of Nursing, B P Koirala Institute of Health Sciences, Dharan, Nepal.
}

\begin{abstract}
Introduction: A high prevalence of psychological/ mental disorders has frequently been reported among nursing staff. However, there is a scarcity of data about' psychological, mental and behavioural problems' among Nepalese nurses. Current study aimed to measure the prevalence of psychiatric problems among nursing staff in a tertiary care hosital.
\end{abstract}

Methods: All nursing staffs working in the hospital during one year were the subjects of this study. With the informed written consent, the responses to semi-structured proforma and the questionnaire General Health Questionnaire 28 were collected. A semi-structured proforma was used to record socio-demographic, clinical profiles and other information. The GHQ 28 was used to screen major psychiatric disorders. The GHQ 28 gives 'psychiatric caseness' to the subjects with score of 4 or more.

Results: Overwhelming majority of nursing staff in BPKIHS is female certificate level staff nurses. Majority were from urban and semi urban settings. Some had job and institute related stressors. Most common among the reported health complaints were low back pain and headache. Few staff revealed psychiatric diagnosis. Among the enrolled 337 subjects, 'psychiatric caseness' was present in $34.72 \%$. Some departments (e.g. dialysis, eye, medical, gynecology ward) had proportionately higher 'psychiatric caseness' rates than other (e.g. ENT, psychiatry ward, emergency OT, CSSD).

Conclusions: A great proportion of nursing staff suffer from mental and behavioral problems.

Keywords: hospital; GHQ 28; mental illness; nursing staff; psychology.

\section{INTRODUCTION}

No one is immune to mental illness and mental illness is ubiquitous. ${ }^{1-2}$ Nurses are not exception; rather studies reveal a greater prevalence of problem than among general population. ${ }^{3-6}$ Different factors: such as individual, profession/institute related and contemporary are reported to play role for such higher prevalences. ${ }^{6-9}$

There is no comprehensive data on this regard from Nepal. Keeping the view of Nepalese context, the problem is anticipated at least not to be less than in other parts. The proper data will raise concern among the stakeholders for addressing this neglected side of health.
Correspondence: Dr. Dhana Ratna Shakya, Department of Psychiatry, B P Koirala Institute of Health Sciences, Ghopa, Dharan, Nepal. Email: drdhanashakya@yahoo.com, Phone: 025-525555, Extension: $3225,5347$. 
This study was carried among all nursing staff to measure the prevalence of psychological problems. Overarching the objectives would be to provide services, formulate appropriate Acts and conduct regular similar studies over times.

\section{METHODS}

A Cross Sectional, Prevalence study of psychiatric problems among nursing staff was conducted in all departments and sections of B P Koirala Institute of Health Sciences (BPKIHS), a tertiary care teaching hospital in eastern Nepal from December 2009-November 2010. All nursing staffs involved in the clinical services of the institute were enrolled in the study. Practically, all nursing staffs giving written informed consent were enrolled in the study. Hence, it's a kind of census prevalence study. When a staff was not available at the time of enrollment or unable to be present to submit the filled forms, the staff followed thrice to enroll the subject with in study period. Those who gave informed written consent and were present in the institute during study period were included.

The study was carried out after the approval of 'institute ethical review board'. Informed written consent was collected from the subject. Strict confidentiality of information was maintained. The data generated would be used either by the investigator for similar cases or the institute.

Research staff explained about the purpose and importance of the study to particular nursing staff. Informed consent was taken from the subject. Sociodemographic data were collected using semi-structured proforma. The subjects were provided with the selfresponse questionnaire 'General health questionnaire (GHQ- 28)'.

The General health questionnaire $(\mathrm{GHQ})^{10}$ is one of the most common screening assessment tools of mental well-being. It is a measure of the common mental health problems/domains of depression, anxiety, somatic symptoms and social withdrawal. Among the 12, 28, 30 or 60 item versions, the GHO 28 is the most widely used one. Besides time considerations, the GHO 28 has been used most widely because it allows for more valid comparisons since it has been used in other working populations.
Each item is accompanied by 4 possible responses, typically being 'not at all', 'no more than usual', 'rather more than usual' and 'much more than usual', scoring from 0 to 3, respectively. The total possible score on the GHO 28 ranges from 0 to 84 and allows for means and distributions to be calculated, both for the global total, as well as for the four sub-scales. Using the alternative binary scoring method (with the two least symptomatic answers scoring 0 and the two most symptomatic answers scoring 1), the 28- and 30-item versions classify any score exceeding the threshold value of 4 as achieving 'psychiatric caseness'. The alternative binary scoring method was used in this study.

If the GHQ score were compared with the results of independent psychiatric assessment, it would be more likely than not $(0.51)$ to be assessed as being a 'case' once the threshold is exceeded. Hence, 'caseness' is operationally defined as score of 4 or more when the particular respondent is likely to suffer from 'psychiatric disorder' and needs an attention. Reliability coefficients have ranged from 0.78 to 0.95 in various studies. The GHO 28 is simple to administer and score, and is widely used in many studies of (occupational) well-being.

The responses were collected, the information were entered into a computer and analyzed using 'Statistical Package for Social Science' (SPSS) - software.

\section{RESULTS}

The nursing staffs are major working force of different departments of the institute. The top 5 departments absorbing greatest number of nursing staff were: Emergency, ICU/Nursery, Paying, Pediatric and Post natal wards.

Maximum subjects 306 (90.8\%) were female, only one subject responded as male and 30 did not answer.

Classified as per the GON, 2007 for 'Free Health services, DHS Report 2064', the commonest ethnicities among the nurses here were upper hill and disadvantaged hill janajatis (Table1). 
Table 1. Caste/ Ethnicity distribution of Nursing staff.

\begin{tabular}{ll}
\hline Caste/ ethnicity & $\mathbf{n}(\%)$ \\
\hline Unanswered & $118(35.01)$ \\
\hline Upper hill & $83(24.63)$ \\
\hline Upper Terai & $20(5.93)$ \\
\hline Relatively advanced janajati & $32(9.50)$ \\
\hline Disadvantaged non-dalit Terai & $0(0.00)$ \\
\hline Disadvantaged hill janajati & $6(1.78)$ \\
\hline Disadvantaged Terai janajati & $66(19.58)$ \\
\hline Dalit hill & $9(2.67)$ \\
\hline Dalit Terai & $3(0.89)$ \\
\hline Total & $337(100.00)$ \\
\hline
\end{tabular}

Majority of the cases (67\%) were in the age groups of 20-25 and 26-30 years. Average age: 27.38, minimum: 19, maximum: 57 (Table 2).

Table 2. Age distribution of Nursing staff.

\begin{tabular}{|l|l|}
\hline Age (in years) & $\mathrm{n}(\%)$ \\
\hline$<20$ & $1(0.30)$ \\
$20-25$ & $162(48.07)$ \\
\hline $26-30$ & $67(19.88)$ \\
$31-35$ & $16(4.75)$ \\
$36-40$ & $12(3.56)$ \\
$41-45$ & $5(1.48)$ \\
\hline $46-50$ & $9(2.67)$ \\
\hline$>50$ & $11(3.26)$ \\
\hline Not responded & $54(16.02)$ \\
\hline
\end{tabular}

Half of the subjects 167 (49.55\%) were single, $43.92 \%$ (148) married, 1 separated and 1 widow, and $20(5.93 \%)$ did not answer. Many 134 (39.76\%) were staying alone and $102(30.27 \%)$ with their family in the institute. About $30 \%$ (101) did not respond to the question. Many 134 (39.76\%) were from nuclear, 102 (30.27\%) from joint family, and 101 (29.97\%) did not answer.

Out of total married staffs (148), 140 answered the question about the issues/ children. Out of the responding staff, (104) had issues. Average number of the offspring/ children was 1.46. Spouses, i.e. husband of the nurses were from various professions: retired 1 , service 23 , bussiness 20 , teaching 5 , health professional 5, manual worker/ labour 4, abroad works 5 , and other plus unaswered 85.
Among respondents, $42(12.46 \%)$ had educational degree of ANM, 249 (73.89\%) PCL nursing, 24 (7.12\%) B/Sc. Nursing and higher and 22 (6.52\%) did not answer. Majority of the nursing staff work in the post of staff nurse with certificate level of nursing education (Figure 1).

\section{Current post of Nursing staff}

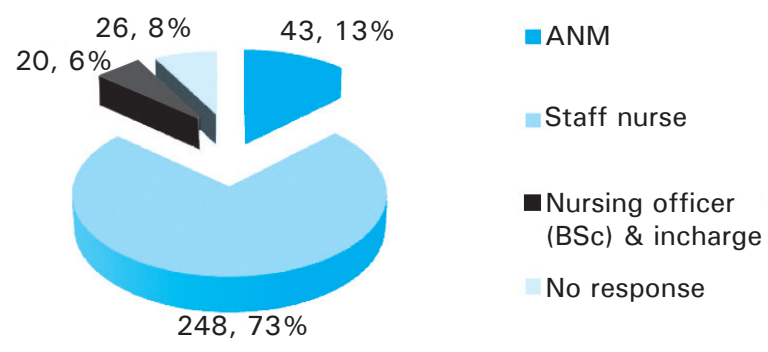

Figure 1. Current post of Nusing staff.

Most nurses had a work experience in BPKIHS of (1-3) and $>5$ years duration. Average duration was 4.76 (minimum- maximum: 0.1-20) years.

Less, $10.09 \%$ came from rural; more $24 \%$ semi-urban; and most $41 \%$ urban settings. One fourth (82, $24.33 \%$ ) did not respond. Average distance from the home or residence of these nurses to the institute was 62.8510 to 700$) \mathrm{Kms}$. Most of responding subjects (103) were from the distance of within $100 \mathrm{Kms}, 17$ from 100-300 Kms and 6 more than $300 \mathrm{Kms}$. Majority 211 (62.61\%) did not respond.

Many 48 (14.24\%) admitted to have some stressors, more 87 (25.82\%) no stressor after they joined BPKIHS and the most 202 (59.94\%) did not answer. Some nurses had work $(5.05 \%)$ and institute related $(3.26 \%)$ stressors.

Only 118 subjects responded to the question about income. Average monthly family income was 27.7 (minimum- maximum: 8- 100) thousands/ month.

The maximum number of the nurses who had some health related complaints $56(16.62 \%)$ at the time of the study expressed physical complaints. Few (6) had psychological ones, that too somatic such as disturbed sleep and appetite and weakness. 222 left unanswered and 59 said no complaint. The most commonly expressed complaints were low back pain, headache and fever (Table 3). 
Table 3. Present health complaints.

\begin{tabular}{|l|r|}
\hline Complaints & $\mathbf{n}(\%)$ \\
\hline Low back pain & $14(4.15)$ \\
\hline Headache & $9(2.67)$ \\
\hline Fever & $9(2.67)$ \\
\hline Other physical & $8(2.37)$ \\
\hline BP related & $5(1.48)$ \\
\hline Infections & $5(1.48)$ \\
\hline Other aches/pain & $4(1.19)$ \\
\hline Skin problems & $4(1.19)$ \\
\hline Gl problems & $4(1.19)$ \\
\hline Eye/ ENT problems & $4(1.19)$ \\
\hline Sleep problems & $4(1.19)$ \\
\hline Diabetes mellitus & $2(0.59)$ \\
\hline Surgical/ orthopedic & $2(0.59)$ \\
\hline Disturbed appetite & $2(0.59)$ \\
\hline Weakness & $2(0.59)$ \\
\hline Unanswered & $222(65.88)$ \\
\hline
\end{tabular}

Many (54 subjects) revealed family members suffering from illness, only 3 mental diagnosis ( 1 also with physical one).

Only two subjects admitted to have problem substance use, 136 did not respond and 199 denied it. Many (58) subjects revealed to be suffering from illness, but only 2 revealed mental diagnosis ( 1 also with physical one). Among the common diagnoses were: hypertension $(4.45 \%)$ and some orthopedic problems $(3.57 \%)$ and specific diagnosis not mentioned (2.37\%). Great majority did not answer, more so about mental illness (Table 4).
Table 4. Major Physical/ Mental disorder reported by

\begin{tabular}{lc} 
respondents. & \\
\hline Major Illness & $\mathbf{n}(\%)$ \\
\hline Absent & $180(53.41)$ \\
\hline Present & $58(17.21)$ \\
\hline No response & $100(29.67)$ \\
\hline Yes, but disease not mentioned & $8(2.37)$ \\
\hline Cardiovascular/ hypertension & $15(4.45)$ \\
\hline Orthopedic & $12(3.56)$ \\
\hline Infectious & $6(1.78)$ \\
\hline Diabetes mellitus & $5(1.48)$ \\
\hline Surgical & $5(1.48)$ \\
\hline Neurological/ seizures & $4(1.19)$ \\
\hline Eye/ ENT & $3(0.89)$ \\
\hline Gastrointestinal & $2(0.59)$ \\
\hline Metabolic/endocrinological & $2(0.59)$ \\
\hline Gynecological/genitourinary & $1(0.30)$ \\
\hline Tumor/ cancer & $1(0.30)$ \\
\hline Respiratory/ chest & $1(0.30)$ \\
\hline Dermatological & $1(0.30)$ \\
\hline Psychiatric & $2(0.59)$ \\
\hline
\end{tabular}

Out of total 28 score, as per the GHQ 28 manual, score of 4 or more has been adopted as 'psychiatric caseness'. This way, 117 (34.72\%) subjects had 'psychiatric caseness'.

The departments with the highest psychiatric caseness among the nurses were: Dialysis, Eye ward, Medical wards, Gynecology OT, Emergency, Postnatal ward; and those with the least were: ENT, ward, Nursery/ ICUs, Psychiatry, Emergency OT, Delux, CSSD (Table 5). 
Table 5. Departmental distribution of 'Psychiatric caseness' Prevalence.

\begin{tabular}{|c|c|c|c|}
\hline Departments & Total staff & $\begin{array}{c}\text { Psychiatric caseness } \\
\text { ( } \% \text { of total) }\end{array}$ & $\begin{array}{l}\text { Psychiatric caseness } \\
\% \text { of department staff }\end{array}$ \\
\hline Dialysis & 11 & $8(2.37)$ & 72.73 \\
\hline Eye & 9 & $6(1.78)$ & 67.67 \\
\hline Medical ward & 24 & $16(4.75)$ & 66.67 \\
\hline Gynecology OT & 14 & $9(2.67)$ & 64.29 \\
\hline Emergency & 33 & $17(5.05)$ & 51.52 \\
\hline Post natal ward & 25 & $11(3.26)$ & 44.00 \\
\hline Antenatal / labour ward & 12 & $5(1.48)$ & 41.67 \\
\hline Gynecology ward & 11 & $4(1.19)$ & 36.37 \\
\hline Total & 337 & $117(34.72)$ & 34.72 \\
\hline Day care OT & 3 & $1(0.30)$ & 33.33 \\
\hline $\mathrm{MCH}$ & 11 & $3(0.89)$ & 27.27 \\
\hline Paying & 30 & $8(2.37)$ & 26.67 \\
\hline Pediatric ward & 27 & $7(2.08)$ & 25.93 \\
\hline Orthopedic ward & 12 & $3(0.89)$ & 25.00 \\
\hline Dermatology ward & 10 & $2(0.59)$ & 25.00 \\
\hline CSSD & 9 & $2(0.59)$ & 22.22 \\
\hline ICU/ CCU/ Delux & 29 & $6(1.78)$ & 20.69 \\
\hline Emergency OT & 12 & $2(0.59)$ & 16.67 \\
\hline Psychiatry & 13 & $2(0.59)$ & 15.38 \\
\hline NICU/ PICU/ Nursery & 33 & $4(1.19)$ & 12.12 \\
\hline ENT & 9 & $1(0.30)$ & 11.11 \\
\hline
\end{tabular}

The top scoring 3 items of GHQ 28 were: A3. Feeling run down and out of sorts A5. Pains in head and B4. Getting edgy and bad tempered (Table 6). 
Table 6. GHO 28 Item distribution (with scores $\geq 2$ or scored 1 by binary method).

\begin{tabular}{|c|c|c|}
\hline Subscore domen & GHO 28 Item & n (\%) \\
\hline A1 & Well and good health & $26(7.72)$ \\
\hline A2 & Need of a tonic & $58(17.21)$ \\
\hline A3 & Feeling run down \& out of sorts & $90(26.71)$ \\
\hline A4 & Feeling ill & 64 (18.99) \\
\hline A5 & Pains in head & $79(23.44)$ \\
\hline A6 & Tightness or pressure in head & $48(14.24)$ \\
\hline A7 & Hot or cold spells & $38(11.28)$ \\
\hline B1 & Loss sleep over worry & $56(16.62)$ \\
\hline B2 & Difficulty sleeping once off & $48(14.24)$ \\
\hline B3 & Constantly under strain & 64 (18.99) \\
\hline B4 & Getting edgy and bad tempered & $78(23.15)$ \\
\hline B5 & Getting panicky or scared & $28(8.31)$ \\
\hline B6 & Finding everything on top of self & $53(15.73)$ \\
\hline B7 & Feeling nervous and strung up & 35 (10.39) \\
\hline C1 & Manage to keep busy \& occupied & $26(7.72)$ \\
\hline $\mathrm{C} 2$ & Taking longer over the things & $17(5.05)$ \\
\hline C3 & Doing things well & $11(3.26)$ \\
\hline $\mathrm{C} 4$ & Satisfaction over the task & $43(12.76)$ \\
\hline C5 & Playing useful part in things & $17(5.05)$ \\
\hline $\mathrm{C} 6$ & Capable of making decisions & $28(8.31)$ \\
\hline $\mathrm{C7}$ & Able to day to day activities & $34(10.09)$ \\
\hline D1 & Thinking self worthless & $24(7.12)$ \\
\hline D2 & Feel that life is hopeless & $33(9.79)$ \\
\hline D3 & Feel that life isn't worth living & $11(3.26)$ \\
\hline D4 & Thought of taking away with self & $25(7.42)$ \\
\hline D5 & Unable to do things as nerves bad & $19(5.64)$ \\
\hline D6 & Wishing self dead & $14(4.15)$ \\
\hline D7 & Rumination of suicidal thoughts & $15(4.45)$ \\
\hline
\end{tabular}

\section{DISCUSSION}

Current study has been carried out in B P Koirala Institute of Health Sciences, Dharan, Nepal to determine the prevalence of psychiatric problem among nursing staff in the pretext of the constraints of time, resources and baseline data. This is the first of its kind from Nepal, to the knowledge of the author. All the nursing staffs involved in clinical services of all categories, including ANM, staff nurse, nursing officer and nursing incharges, were the subjects of this study. Out of the total of 486 (2009/2010) in the institute, we could enroll 337 (69.34\%). Three attempts were made for a subject, at most to enroll within study period. Not giving consent, not available every time while approached by the research team in various modes and not returning the responses were the main reasons of the failure to enroll some subjects.
Psychiatric diagnoses were screened with a standard self response questionnaire 'General health questionnaire 28' (GHQ 28). This self response tool is widely validated across the world, also among nursing staff. ${ }^{3}$, 4, 10, 12 In all questions, the respondents should choose the most appropriate one from 4 alternative answers for their condition. The $3^{\text {rd }}$ and $4^{\text {th }}$ responses i.e. 'worse than usual' and 'much more than usual' were scored as significant for 'psychiatric caseness'. The total score of 4 or more was taken as 'psychiatric caseness' i.e. the condition where one is supposed to be more likely than not to be suffering from psychiatric disorder and in need of professional help. ${ }^{10}$ To facilitate the understanding among low level staff, i.e. ANM, we had included the Nepalese translation along with the original English sentence. Since our subjects were health professionals with health background and also working in an institute with mental health services. ${ }^{13}$ Not the responses were 
likely to be realistic.

Despite of failure to enroll subjects, mainly from department of Emergency and family medicine, the department of emegency and family medicine had the most number of nursing staffs in BPKIHS. Other departments with major nursing man power force were: various ICUs, Paying, Post-natal, Medical, Pediatric and Gynecology wards. A great majority of nursing staffs here were female. This clearly reflects the Nepal's stand about recruitng female students for nursing profession which once used to enroll male as well for some period, but currently stopping the male enrollment. This finding is similar to the study looking into the view of nursing students and staffs of BPKIHS about 'electroconvulsive therapy' (ECT). ${ }^{14}$

The caste/ ethnicity of the subjects was categorized as per the one adopted for 'health service utilization' of Government of Nepal. The most common ethnicities are upper hill (e.g. Brahmin, Chhetri, Thakuri, etc.), disadvantaged hill janajatis (e.g. Magar, Tamang, Rai, Limbu) and relatively advanced janajatis (e.g. Newar, Gurung, Thakali). Brahmins exceeded other caste/ ethnicity groups among nursing staffs, not keeping with general population structure. The presence of disadvantaged and 'dalits' were less though our institute has provision of enrollment seats for different such categories of people from various background such as hilly area and disadvantaged groups for nursing education. These well known but not objectively documented findings of dominance of some castes over other may, in part reflect the discrimination in different sectors including nursing/ medical education. ${ }^{15}$

Nearly half of the subjects were single, slightly less were married, and one separated and widower each, and some did not answer. The good representation of single status is consistent with the over representation of staff nurse with certificate level of qualification. This is mainly because many subjects were in the formative years, their focus was study and there has been a trend of first making career before marriage reflected in gradual increase in 'singulate mean age at marriage' of both male and female of Nepal in last decades. ${ }^{16}$

Nearly three fourths of nursing force has qualification of certificate level, many have ANM training and less bachelor degree. In the Nepalese pretext of gradually advancing career, low man power and the institute at the same time being teaching institute of tertiary care level running various nursing academic programs from certificate to master levels, this distribution is realistic depiction. Two thirds of the staffs $(67 \%)$ were in the age range of 20-30 years. It is understandable since this institute mainly has nursing staff working as staff nurse with PCL qualification as a major chunk. The average age of the subjects was 27.38 with minimum of 19 and maximum 57 years. This is consistent with the finding of same institute regarding ECT studies among nurses. ${ }^{14}$

To have idea about family and related stressors, we explored into various family aspects. About $40 \%$ were staying alone far from family, 30\% were living with their family in the institute and nearly $30 \%$ did not respond to the question. Many of the subjects (about $40 \%$ ) were from nuclear, $30 \%$ from joint family, and nearly $30 \%$ did not answer. This clearly shows the trend of Nepali family structure changing from typical joint family towards nuclear type as shown in other studies. ${ }^{17}$ Among the total married staffs (148), 140 answered the question about the issues/ children. Out of the responding staff, (104) had issues. Average number of the offspring/ children was 1.46. This reflects the current trend of 1 or 2 children among people, especially educated family in Nepal. Spouses, i.e. husband of the nurses were from various professions, such as: service, bussiness, teaching, health professional, manual/ labour, abroad works, and others. Only 118 subjects responded to the question about their monthly family income. Average family income from the respondants was 27.7 (minimum- maximum: 8-100) thousands per month.

Only $10 \%$ nursing staffs came from villages, $25 \%$ from semi-urban, the most $41 \%$ urban settings and $24 \%$ did not respond. Average distance from the home or residence of these nurses to the institute was 62.85 $\mathrm{Kms}$ (0 to $700 \mathrm{Kms}$ ). Hundred and three subjects were from the distance of within $100 \mathrm{Kms}, 17$ from 100$300 \mathrm{Kms}$ and 6 more than $300 \mathrm{Kms}$ and 211 (63\%) did not answer. These findings reflect the institute, situated in a city surrounded by villages to home staff from different settings in eastern Nepal.

Medical/ nursing profession is one of the stressful careers. ${ }^{6}$ In this study, only some subjects 48 (14.24\%) admitted to have stressors, $87(25.82 \%)$ denied any stressor after they joined BPKIHS and 202 (59.94\%) did not answer. Some nurses had work/ job and institute related stressors. In UK, a developed country too, similar stressors were reported, such as: increasing bureaucratisation of health care, unattractive working conditions, poor pay and the emotionally exhausting nature of the work were associated with high rates of burnout and workplace violence. ${ }^{6}$ Few staff reported ragging and bullying in this study. Ragging was one of the most common stressors among medical students of the same institute, including nursing students. ${ }^{15}$ Bullying of nursing staffs is increasingly being reported from many other places. ${ }^{7}$ 
The maximum number of the nurses with health related complaints $(56,16.62 \%)$ expressed physical complaints at the time of the study; only few (6) had psychological, that too somatic such as disturbed sleep and appetite and weakness. There was a tendency not to answer the questions in many aspects, including about health, more so about mental. Majority (222) left unanswered and 59 said no complaint. The most common complaints were low back pain, headache and fever. The low back pain has been found common among nursing staffs in other parts of the world as well. ${ }^{18}$ Seventeen percent (58) subjects revealed to be suffering from some diseases/illness, out of that only two had revealed mental diagnosis (one also with physical one). Among the common diagnoses were: hypertension $(4.45 \%)$ and some orthopedic problems (3.57\%). About thirty percent subjects did not respond to the question. Hypertension is among the most reported morbidity in all populations. Similarly common psychiatric diagnosis depression however was not mentioned by the nursing subjects here. ${ }^{1}$ The proportion of subjects depicted as 'psychiatric caseness' with GHO 28 is much more than the revealed psychiatric diagnosis, not coinciding with the small figure of subject with mental diagnosis. Despite of nursing profession with some knowledge on mental health and illness ${ }^{19}$, psychiatric diagnosis appears to be associated with stigma, humiliation and misconception. It needs to be addressed with due attention. The orthopedic problem here was basically the one leading to low back pain, coinciding with the health complaint data. Similar tendency of under/reporting was seen about illness of family members. Similar thing was seen about the substance use problem too. Only two subjects admitted to have problem substance use, 136 did not respond and 199 denied it. Alcohol is the most commonly used substance in Nepal, also among female i.e. the majority of our subjects. ${ }^{20}$

In GHO 28, we adopted the response in the $3^{\text {rd }}$ (worse than usual) or $4^{\text {th }}$ (much worse than usual) column as significant for 'psychiatric caseness'. In this way, the top scored 3 items of GHQ 28 were: A3. Feeling run down and out of sorts, A5. Pains in head and B4. Getting edgy and bad tempered. Out of total 28 score, as per the manual ${ }^{10}$, score of 4 or more has been adopted as 'psychiatric caseness. In this way,
$117(34.72 \%)$ subjects had 'psychiatric caseness'. This figure of the psychiatric disorders among nursing staff working in different departments is over all less than that seen among those looking after advanced cancer patients ${ }^{3}$ which is comparable to the figure of psychiatric caseness in some departments like dialysis, medical ward, gynecology OT, emergency and post natal ward. High score on GHO 28 is comparable with the finding of KR Perkes. ${ }^{4}$ The departments with the highest psychiatric caseness among nurses here were: 1. Dialysis, 2. Eye ward, 3. Medical wards, 4. Gynecology OT, 5. Emergency, 6. Postnatal and those with the least were: 1. ENT ward, 2. Nursery/ ICUs, 3. Psychiatry ward, 4. Emergency OT, 5. Delux, and 6. CSSD unit.

These findings/ observations corroborate that nursing staffs suffer from psychiatric disorders; even more than general people. ${ }^{1}$ Hence, all concerned sides including nursing staffs themselves, their family, institute authority and society should remain aware about the fact, maintain alert watch and take timely appropriate steps.

\section{CONCLUSIONS}

There is a tendency not to reveal mental illness among nursing staff of BPKIHS. Low back pain and headaches are commonly expressed health complaints. Hypertension and orthopedic diagnoses are commonly revealed diagnoses. A great proportion of nursing staffs (one third) suffer from mental illness, the prevalence is higher than commonly reported prevalence of general population. The prevalence is higher in departments like dialysis, eye, medical, gynecological wards and emergency than in others like ENT, nursery, psychiatry, delux and CSSD.

\section{ACKNOWLEDGEMENTS}

The author expresses sincere thanks to College of Nursing and all staff for their kind cooperation, to Mr. DD Baral for his statistical assistance, Dr. Kevan Thorley (UK) for his help during manuscript write-up and BPKIHS for institute research grant.

\section{REFERENCES}

1. Murray CL, Lopez AD. The Global Burden of Disease: a Comprehensive Assessment of Mortality and Disability from Diseases, Injuries, and Risk Factors in 1990 and Projected. Cambridge, Mass: Harvard University Press; 1996.

2. Satcher D. Mental Health: A Report of the Surgeon General. Washington, DC: Government Printing Office; 1999.
3. Vachon ML. Measurement and management of stress in health professionals working with advanced cancer patients. Death Education. 1978;6:365-78.

4. Perkes KR. Social desirability and self-report psychiatric inventory scores. Psychological Medicine. 1980;10:735-42. 
5. Borrill CS, Wall TD, West MA. Mental Health of the Workforce of the NHS Trusts, Phase 1: Final Report. Sheffield/Leeds: Institute of Work Psychology, University of Sheffield, and Department of Psychology, University of Leeds; 1996.

6. Nolan P, Smojkis M. The mental health of nurses in the UK. Advances in Psychiatric Treatment. 2003;9:374-9.

7. Einarsen S, Matthiesen SB, Skogstad A. Bullying, burn-out and psychological well-being among assistant nurses. J Occup health Safety. 1998;14(6):563-8.

8. Thomas B. Management strategies to tackle stress in mental health nursing. Mental Health Care. 1997;1:15-6.

9. Callaghan P, Tak-Ying SA, Wyatt PA. Factors related to stress and coping among Chinese nurses in Hong Kong. J Adv Nurs. 2000 Jun;31(6):1518-27.

10. Goldberg DP et al. Manual of General health questionnaire. Windsor, England: NFER Publishing; 1978.

11. Craig J. The General health questionnaire. Occupational medicine. 2007;57:79.

12. Lim LCC, Chew SJ. Validation of the General health questionnaire in female video display unit (VDU) operators in Singapore. Singapore medical J. 1991;32:143-5.

13. Shakya DR, Pandey AK, Shyangwa PM, Shakya R. Psychiatric morbidity profiles of referred Psychiatry OPD patients in a general hospital. Indian Medical Journal. 2009 Dec;103(12):407-11.
14. Shakya DR, Lama S. Electro-convulsive therapy (ECT)- In the eyes of nurses of a tertiary care hospital. Health Renaissance. 2010;8(2):4-8.

15. Shakya DR, Shyangwa PM, Shakya R, Agrawal CS. Mental and behavioral problems in medical students of BPKIHS. Abstract Book of XVI Anniversary Scientific program of BPKIHS 2009; pp.107.

16. Central Bureau of Statistics, Nepal. Population Trend and Selected Indicators of Nepal, 1971- 2006. Nepal Demographic and Health Survey, 2006 MOES 2006. In: Nepalinfo 2007. Available at: http://www.cbs.gov.np/population_profile. php. Accessed at 18.05.2010.

17. Goldstein MC, Beall CM. Family change, caste, and the elderly in a rural locale in Nepal. Journal of cross-cultural Gerontology. 1986;1(3):305-16. Abstract accessed at: http:// www.springerlink.com/content/w186841146035531/. (Accessed at 18.05.2010)

18. Roupa Z, Vassilopoulos A, Sotiropoulou P, Makrinika E, Noula M, Faros E et al. The Problem of Lower Back Pain in Nursing Staff and its Effect on Human Activity. Health science journal. 2008;2(4):219-25.

19. Shyangwa PM, Singh S, Khandelwal S K. Knowledge and attitude about mental illness among Nursing staff. J Nepal Med Assoc. 2003;42:27-31.

20. Niraula SR, Shyangwa PM, Jha N, Paudel RK, Pokharel PK. Alcohol use among women in a town of Eastern Nepal. J Nepal Med Assoc. 2004;43:244-9. 